\title{
単語リストと生コーパスによる確率的言語モデルの分野適応
}

\begin{abstract}
森信 介 $^{\dagger}$
本論文では，単語リストと生コーパスが利用可能な状況における確率的言語モデルの 分野適応について述べる。このような状況の下での一般的な対処は，単語リストを語 彙に加えた自動単語分割システムによる生コーパスの自動単語分割の出力文を可能な 限り人手で修正し，パラメータ推定に利用することである。しかしながら，文単位で の修正では，正確な単語分割が容易でない箇所が含まれることになり，作業効率の著 しい低下を招く，加えて，文単位で順に修正していくことが，限られた作業量を割り 当てる最良の方法であるかということも疑問である。本論文では，コーパスの修正を 単語単位とし，修正箇所を単語リストで与えられる適応分野に特有の単語に集中する ことを提案する。これにより, 上述の困難を回避し, 適応分野に特有の単語の統計的 な振る舞いを捕捉するという, 適応分野のコーパスを利用する本来の目的にのみコー パス修正の作業を集中することが可能となる. 実験では, 自動単語分割の結果の人手 による修正の程度や方法を複数用意し, その結果得られるコーパスから推定された確 率的言語モデルの予測力やそれに基づく仮名漢字変換の精度を計算した。この結果, 適応分野に特有の語彙の出現箇所に修正のコストを集中することにより, 少ない作業 量で効率良く確率的言語モデルを分野適応できることが分かった.
\end{abstract}

キーワード： 仮名漢字変換, 音声認識, 言語モデル, コーパス

\section{Language Model Adaptation with a Word List and a Raw Corpus}

\author{
SHINSUKE MORI ${ }^{\dagger}$
}

In this paper, we discuss stochastic language model adaptation methods given a word list and a raw corpus. In this situation, a general method is to segment the raw corpus by a word segmenter equipped with a word list, correct the output sentences annotated with word boundary information by hand, and build a model from the segmented corpus. In this sentence-by-sentence error correction method, however, the annotator encounters difficult points and this results in a decrease of the productivity. In addition, it is not sure that sentence-by-sentence error correction from the beginning is the best way to dispense a limited work force. In this paper, we propose to take a word as a correction unit and concentrically correct the positions in which words in the list appear. This method allows us to avoid the above difficulty and go straight to capture the statistical behavior of specific words in the application field. In the experiments, we compared the language models built by several methods from the corpora in predictive power and Kana-kanji conversion accuracy. The results showed that concentrating on the error correction around the words in the list, we can build a better language model with less effort.

KeyWords: kana-kanji convertor, speech recognition, language model, corpus 


\section{1 まえがき}

確率的言語モデルは，文字列を出力とする言語処理において幅広く用いられている．音声 認識システム (Jelinek 1985) の多くが, 解選択において, 音響モデルとともに確率的言語モデ ルを参照する．文字誤り訂正 (Nagata 1996) や仮名漢字変換 (森, 土屋, 山地, 長尾 1999) にお いても, 確率的言語モデルを用いる方法が提案されている.さらに，機械翻訳 (Brown, Cocke, Pietra, Pietra, Jelineck, Lafferty, Mercer, and Roossin 1990) や文書の整形 (下岡, 南條, 河原 2004) などにも応用されている.

多くの確率的言語モデルは単語や単語列の頻度に基づいており，これは正しく単語に分割さ れた例文 (単語分割済みコーパス) に対して計数される。この単語分割済みコーパスは，一般的 と考えられる分野においては既に利用可能となっているが，新たに確率的言語モデルを用いる 分野 (医療現場やコールセンターでの音声認識など) の言語資源としては，単語に分割されてい ない例文 (生コーパス) やその分野の単語リストのみが利用可能であることが多い.このような 状況の下での一般的な対処は，単語リストを語彙に加えた自動単語分割システム (Nagata 1994) により生コーパスの各文を単語に分割し，可能な限り多くの文の分割結果を人手で修正し，自 動解析の結果と合わせて単語分割済みコーパスとすることである.

単語分割の修正量は，多ければ多いほど統計結果の信頼性が増し，確率的言語モデルの能力 は高くなる。しかしながら，単語分割の修正作業にはコストや時間がかかるので，コーパスの 一部分を修正の対象とし，残りの部分に関しては自動分割の結果をそのまま用いるということ がしばしば行なわれる。文単位で修正する場合には，文法の専門家でさえも正確な単語分割が 容易でない機能語列などの箇所が必然的に含まれることになるが，このようなの箇所での分割 方針を作業者に徹底することは非常に困難であり，作業効率の著しい低下を招く．加えて，文 単位で順に修正していくことが，限られた作業量を割り当てる最良の方法であるかということ も疑問である (Hakkani-Tür, Tur, Rahim, and Riccardi 2004) .

本論文では，コーパスの修正を一文単位ではなく単語単位とし，修正箇所を単語リストなど で与えられる適応分野に特有の単語の周辺に集中することを提案する。これにより，上述のよ うな困難を回避することが可能となり，さらに，適応分野に特有の単語の統計的な振る舞いを 捕捉するという，適応分野のコーパスを利用する本来の目的にコーパス修正の作業を集中する ことが可能となる。このようにして得られるコーパスは一部分の単語境界情報のみが正確であ る文を含む.このようなコーパスから有限の語彙に対して確率的言語モデルを推定するために， 本論文では，生コーパスから無限の語彙に対して確率的言語モデルを推定する方法 (Mori and Takuma 2004) を語彙が有限の場合に応用する方法について述べる.

実験では, 生コーパスの単語境界の人手による修正の程度や方法を複数用意し, その結果得 られるコーパスから推定される確率的言語モデルの予測力やそれに基づく仮名漢字変換の精度 を計算した。実験の結果，単語リストの各単語に対して 2 䇢所の出現のみを人手でマークする 
方法では，単語数の割合にして生コーパス全体の $5.22 \%$ 修正により，単語数の割合にして生 コーパス全体の $45.00 \%$ の文を文単位で修正した場合と同程度の仮名漢字変換の精度を達成する ことができた。また，単語リストの各単語に対して全ての出現箇所を人手でチェックすること で，コーパス全体に対して自動分割の結果を人手で修正するのと同程度の予測力と変換精度を 達成できた。この結果から，適応分野に特有の語彙の出現箇所に修正のコストを集中すること により，少ない作業量で効率良く確率的言語モデルを分野適応できるといえる.

\section{2 確率的言語モデル}

自然言語処理における確率的言語モデルの役割は，与えられた文字列がある言語の文である 尤度を数值化することである．確率的言語モデルに基づく言語処理は，候補から解を選択する 際にこの尤度を参照する。自動単語分割は解析系の一例であり, 文字列が与えられると尤度が 最大になる単語の列を計算する。認識系の代表例の音声認識では，音響信号列を入力として， 尤度が最大となる文字列を算出する際に，音響モデルと併せて確率的言語モデルを参照する。

\section{1 確率的言語モデル}

最も一般的な言語モデルは，単語 $w$ を単位とする $n$-gram モデル $M_{w, n}$ である。このモデル は，文を単語列 $\boldsymbol{w}_{1}^{h}=w_{1} w_{2} \cdots w_{h}$ ( $h$ は単語数) とみなし，これらを文頭から順に予測する ${ }^{1}$.

$$
M_{w, n}\left(\boldsymbol{w}_{1}^{h}\right)=\prod_{i=1}^{h+1} P\left(w_{i} \mid \boldsymbol{w}_{i-n+1}^{i-1}\right)
$$

この式の中の $w_{i}(i \leq 0)$ は, 文頭に対応する特別な記号であり, $w_{h+1}$ は，文末に対応する特別 な記号である．完全な語彙を定義することは不可能であるから，未知語を表わす特別な記号 UT を用意する。未知語の予測の際は，まず，単語 $n$-gram モデルによりUT を予測し，さらにその 表記を文字 $x$ の列 $\boldsymbol{x}_{1}^{h^{\prime}}$ ( $h^{\prime}$ は文字数) とみなし, 文字を単位とする $n$-gram モデル $M_{x, n}$ によっ て以下のように予測する。

$$
M_{x, n}\left(\boldsymbol{x}_{1}^{h^{\prime}}\right)=\prod_{i=1}^{h^{\prime}+1} P\left(x_{i} \mid \boldsymbol{x}_{i-n+1}^{i-1}\right)
$$

この式の中の $x_{i}(i \leq 0)$ は, 語頭に対応する特別な記号であり， $x_{h^{\prime}+1}$ は, 語末に対応する特別 な記号である。したがって， $w_{i}$ が未知語の場合には以下のように予測される ${ }^{2}$.

$$
P\left(w_{i} \mid \boldsymbol{w}_{i-n+1}^{i-1}\right)=M_{x, n}\left(w_{i}\right) P\left(\mathrm{UT} \mid \boldsymbol{w}_{i-n+1}^{i-1}\right)
$$

1 以下では, 太字は列を表すとし, 必要に応じて最初の要素の添字を右下に, 最後の要素の添字を右上に書くこととする。 2 正確には, 履歴 $\boldsymbol{w}_{i-n+1}^{i-1}$ に含まれるすべての未知語はUTに置き換えられ同一視される。 


\section{2 応用}

確率的言語モデルの応用は，自然言語認識と自然言語解析に大別できる.

認識系の代表例は，音声認識である。確率的言語モデルを用いる音声認識では，以下の式の ように，音響特徵量の列 $s$ を入力とし，語彙 $\mathcal{W}_{k}$ のクリーネ閉包 (空列を含む任意長の文字列 の集合)のうち, 確率最大となる要素 (単語列) $\boldsymbol{w}$ を出力する.

$$
\hat{\boldsymbol{w}}=\underset{\boldsymbol{w} \in \mathcal{W}_{k}^{*}}{\operatorname{argmax}} P(\boldsymbol{s} \mid \boldsymbol{w}) P(\boldsymbol{w})
$$

この式における $P(\boldsymbol{w})$ が確率的言語モデルである。確率的言語モデルの予測力と認識系の精度 との関係は，解析的に導出できるような確固とした関係ではない．音声認識に対して実験的に 得られた関係として, 西村ら (西村, 伊東, 山崎, 荻野 1997) は相関係数 0.6 を報告している.

解析系の代表例は, 単語分割 (と品詞付与)である. 確率的言語モデルによる単語分割 (Nagata 1994) は, 以下の式が示すように, ある言語の文字列 $\boldsymbol{x}$ を入力とし, 生成確率が最大となる単 語列 $\boldsymbol{w}$ を出力する.

$$
\hat{\boldsymbol{w}}=\underset{\boldsymbol{w}=\boldsymbol{x}}{\operatorname{argmax}} P(\boldsymbol{w})
$$

ここで $\boldsymbol{w}=\boldsymbol{x}$ は，単語列 $\boldsymbol{w}$ を文字列とみなした場合，入力 $\boldsymbol{x}$ と等しいことを表す.

\section{3 単語リストと生コーパスによる分野適応}

この節では, 適応対象の分野の単語リストと, それらが出現する生コーパスが利用可能であ る場合に，それらから確率的言語モデルを推定する方法を述べる.

\section{1 確率的単語分割コーパスからの単語 $n$-gram 確率の推定}

単語分割済みコーパスは，各文字間に単語境界が存在するか否かの情報が人手により付与さ れている. 生コーパスはこの情報を持たないが, 各文字間に単語境界が存在する確率を付与し, それによって生コーパスを確率的に単語に分割されたコーパス (確率的単語分割コーパス) とみ なすことにより, 無限の語彙に対する単語 $n$-gram 頻度や単語 $n$-gram 確率を計算する方法が提 案されている (Mori and Takuma 2004). 以下では，この方法を説明する.

生コーパス $C_{r}$ (以下, 長さ $n_{r}$ の文字列 $\boldsymbol{x}_{1}^{n_{r}}$ として参照) を所与として, 連続する 2 文字 $x_{i}, x_{i+1}$ の間に単語境界が存在する確率 $P_{i}$ を付与したものを考える. 最初の文字の前と最後の 文字の後には単語境界が存在するとみなせるので, $i=0, i=n_{r}$ の時は便宜的に $P_{i}=1$ とする.

単語 0-gram 頻度 確率的単語分割コーパスにおける単語 $0-\operatorname{gram}$ 頻度 $f_{r}(\cdot)$ は, そのコー パス中の期待単語数であり, 以下のように定義される。

$$
f_{r}(\cdot)=1+\sum_{i=1}^{n_{r}-1} P_{i}
$$




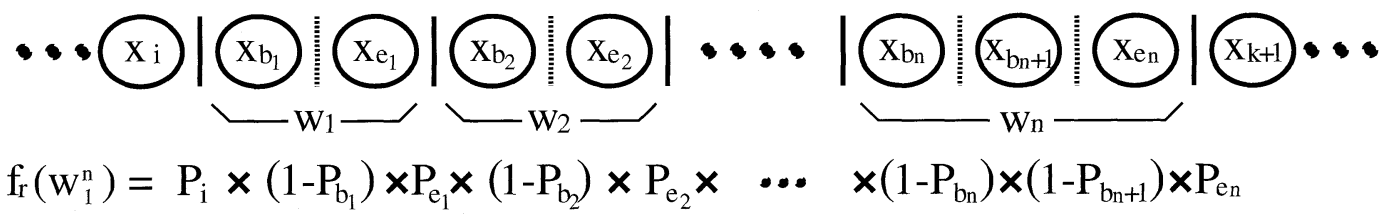

図 1 確率的単語分割コーパスにおける単語 $n$-gram 頻度

単語 1-gram 頻度 確率的に単語分割された生コーパスに出現する文字列 $\boldsymbol{x}_{i+1}^{k}$ が $l=k-i$ 文字からなる単語 $w$ である必要十分条件は以下の 4 つである.

(1) 文字列 $\boldsymbol{x}_{i+1}^{k}$ が単語 $w$ に等しい.

(2) 文字 $x_{i+1}$ の直前に単語境界がある.

(3) 単語境界が文字列中にない.

(4) 文字 $x_{k}$ の直後に単語境界がある.

したがって, 単語 $w$ の生コーパス中の単語 1-gram 頻度 $f_{r}$ は, 単語 $w$ の表記の全ての出 現 $O_{1}=\left\{(i, k) \mid \boldsymbol{x}_{i+1}^{k}=w\right\}$ に対する期待頻度の和として以下のように定義される.

$$
f_{r}(w)=\sum_{(i, k) \in O_{1}} P_{i}\left[\prod_{j=i+1}^{k-1}\left(1-P_{j}\right)\right] P_{k}
$$

単語 $n$-gram 頻度 単語 1-gram 頻度と同様に, $L$ 文字からなる単語列 $\boldsymbol{w}_{1}^{n}=\boldsymbol{x}^{\prime}{ }_{1}^{L}$ の生コー パス $\boldsymbol{x}_{1}^{n_{r}}$ における頻度，すなわち単語 $n$-gram 頻度について考える。このような単語列 に相当する文字列が生コーパスの $(i+1)$ 文字目から始まり $k=i+L$ 文字目で終る文 字列と等しく $\left(\boldsymbol{x}_{i+1}^{k}=\boldsymbol{x}^{\prime}{ }_{1}^{L}\right)$, 単語列に含まれる各単語 $w_{m}$ に相当する文字列が生コーパ スの $b_{m}$ 文字目から始まり $e_{m}$ 文字目で終る文字列と等しい $\left(\boldsymbol{x}_{b_{m}}^{e_{m}}=w_{m}, 1 \leq \forall m \leq n\right.$; $\left.e_{m}+1=b_{m+1}, 1 \leq \forall m \leq n-1 ; b_{1}=i+1 ; e_{n}=k\right)$ 状況を考える (図 1 参照). 単語 1-gram 頻度の計算の場合と同様に, 単語列と生コーパスの部分文字列は, 文字列として 対応していることに加えて，各文字間における単語境界の有無も対応している場合にの み単語列が出現していると考えられる。したがって, 確率的に単語分割されたコーパス に出現する文字列 $\boldsymbol{x}_{i+1}^{k}$ が単語列 $\boldsymbol{w}_{1}^{n}=\boldsymbol{x}^{\prime}{ }_{1}^{L}$ である必要十分条件は以下の 4 つである.

(1) 文字列 $\boldsymbol{x}_{i+1}^{k}$ が単語列 $\boldsymbol{w}_{1}^{n}$ に等しい.

(2) 文字 $x_{i+1}$ の直前に単語境界がある.

(3) 単語境界が各単語に対応する文字列中にない.

（4）単語境界が各単語に対応する文字列の後にある.

したがって, 生コーパスにおける単語 $n$-gram 頻度を以下のように定義することができる.

$$
f_{r}\left(\boldsymbol{w}_{1}^{n}\right)=\sum_{\left(i, e_{1}^{n}\right) \in O_{n}} P_{i}\left[\prod_{m=1}^{n}\left\{\prod_{j=b_{m}}^{e_{m}-1}\left(1-P_{j}\right)\right\} P_{e_{m}}\right]
$$




$$
\begin{aligned}
e_{1}^{n} & =\left(e_{1}, e_{2}, \cdots, e_{n}\right) \\
O_{n} & =\left\{\left(i, e_{1}^{n}\right) \mid \boldsymbol{x}_{b_{m}}^{e_{m}}=w_{m}, 1 \leq m \leq n\right\}
\end{aligned}
$$

とした。

単語 1-gram 確率 決定的に単語に分割されたコーパスからの単語 1-gram 確率の最尤推定 の場合と同様に，確率的単語分割コーパスにおける単語 1-gram 確率を以下のように定義 する。

$$
P_{r}(w)=\frac{f_{r}(w)}{f_{r}(\cdot)}
$$

単語 $n$-gram 確率 決定的に単語に分割されたコーパスからの単語 $n$-gram 確率の最尤推定 の場合と同様に，確率的単語分割コーパスにおける単語 $n$-gram 確率を以下のように定 義する.

$$
P_{r}\left(w_{n} \mid \boldsymbol{w}_{1}^{n-1}\right)=\frac{f_{r}\left(\boldsymbol{w}_{1}^{n}\right)}{f_{r}\left(\boldsymbol{w}_{1}^{n-1}\right)}
$$

\section{2 有限の語彙に対する確率的単語分割コーパスからの単語 $n$-gram 確率の 推定}

確率的言語モデルを用いる音声認識においては，認識される語彙には発音が付与されている 必要がある．また，確率的言語モデルを用いる仮名漢字変換においてもキー入力列が付与され ている表記 (単語) のみが変換結果として出現し得る。このように，現実的な応用では有限の語 彙に対する確率的言語モデルを構築する必要がある。分野適応において単語リストが与えられ ている場合には，一般コーパスから得られる語彙と対象分野の単語リストを語彙として，対象 分野の生コーパスから確率的言語モデルを構築する。この際に，未知語モデルを含めて確率的 言語モデルの条件を満たすためには，未知語記号を含む単語 $n$-gram 確率を正しく定義する必 要がある。

単語分割済みコーパスにおいては，まず語彙 $\mathcal{W}_{k} に$ 属さない単語をコーパスの全ての出現場 所において未知語記号 UT に置き換え，その上で未知語記号を語彙に含まれる単語と同様に扱っ て頻度計算を行なう。決定的に単語に分割されていない確率的単語分割コーパスに対しては, この方法を採ることができない。また，語彙以外の任意の文字列に対する単語 $n$-gram 頻度を 計数しその和を計算する方法も考えられる。語彙以外の任意の文字列は，実際には無限集合で はなく，コーパスの部分文字列のみを対象とすれば十分であるが，これは非常に大きな数とな るので，この計算方法も現実的ではない. しかしながら，単語 $n$-gram 頻度の以下の性質を用 いることにより，確率的単語分割コーパスに対しても未知語記号を含む単語 $n$-gram 頻度を容 
易に計算することができる。

$$
\begin{aligned}
f_{r}\left(\boldsymbol{w}_{u} \mathrm{UT} \boldsymbol{w}_{v}\right) & =\sum_{w \in \mathcal{X}^{+}-\mathcal{W}_{k}} f_{r}\left(\boldsymbol{w}_{u} w \boldsymbol{w}_{v}\right) \\
\sum_{w \in \mathcal{X}^{+}} f_{r}\left(\boldsymbol{w}_{u} w \boldsymbol{w}_{v}\right) & =\sum_{w \in \mathcal{X}^{+}-\mathcal{W}_{k}} f_{r}\left(\boldsymbol{w}_{u} w \boldsymbol{w}_{v}\right)+\sum_{w \in \mathcal{W}_{k}} f_{r}\left(\boldsymbol{w}_{u} w \boldsymbol{w}_{v}\right)
\end{aligned}
$$

ここで $\boldsymbol{w}_{u}, \boldsymbol{w}_{v} \in\left(\mathcal{W}_{k} \cup\{\mathrm{UT}\}\right)^{*}$ は語彙と未知語記号からなる長さ 0 以上の任意の列であり， $\mathcal{X}^{+}$ は文字集合 $\mathcal{X}$ の正閉包 (1 文字以上の任意長の文字列の集合) を表す. 式 (3) の意味は，ある 1 箇所に未知語記号を含む単語 $n$-gram 頻度がその箇所を既知語以外のすべての文字列に置き換 えた単語 $n$-gram 頻度の合計に等しいということである. また式 (4) は, 単語 $n$-gram 頻度にお いてある箇所の単語を任意とした場合の合計が，その箇所が任意の既知語 $\left(\mathcal{W}_{k}\right)$ である場合の 頻度の合計と任意の未知語 $\left(\mathcal{X}^{+}-\mathcal{W}_{k}\right)$ である場合の頻度の合計の和に等しいことを意味する。 式 (3)(4) から, ある 1 箇所に未知語を含む単語 $n$-gram の頻度に対して以下の式が成り立つこ とがわかる゙

$$
f_{r}\left(\boldsymbol{w}_{u} \mathrm{UT} \boldsymbol{w}_{v}\right)=\sum_{w \in \mathcal{X}^{+}} f_{r}\left(\boldsymbol{w}_{u} w \boldsymbol{w}_{v}\right)-\sum_{w \in \mathcal{W}_{k}} f_{r}\left(\boldsymbol{w}_{u} w \boldsymbol{w}_{v}\right)
$$

未知語記号の単語 1-gram 頻度 確率的単語分割コーパスにおける未知語記号の単語 1-gram 頻度 $f_{r}(\mathrm{UT})$ は,コーパスに対して計数した単語 1-gram 頻度と単語 0-gram 頻度に対して 成り立つ関係

$$
f_{r}(\cdot)=\sum_{w \in \mathcal{X}^{+}} f_{r}(w)
$$

と式 (5) において $\boldsymbol{w}_{u}=\boldsymbol{w}_{v}=\varepsilon(\varepsilon$ は空列を表す) とすることで得られる等式

$$
f_{r}(\mathrm{UT})=\sum_{w \in \mathcal{X}^{+}} f_{r}(w)-\sum_{w \in \mathcal{W}_{k}} f_{r}(w)
$$

から以下のように, 単語 0-gram 頻度と語彙に対する単語 1-gram 頻度の和から計算さ れる。

$$
f_{r}(\mathrm{UT})=f_{r}(\cdot)-\sum_{w \in \mathcal{W}_{k}} f_{r}(w)
$$

未知語記号を含む単語 2-gram 頻度 任意の単語 $w_{1} \in \mathcal{W}_{k}$ と未知語記号からなる列の確率 的単語分割コーパスにおける頻度 $f_{r}\left(w_{1} \mathrm{UT}\right)$ はコーパスに対して計数した単語 2-gram 頻 度と単語 1-gram 頻度に対して成り立つ関係

$$
f_{r}\left(w_{1}\right)=\sum_{w \in \mathcal{X}^{+}} f_{r}\left(w_{1} w\right), \quad \forall w_{1} \in \mathcal{W}_{k} \cup\{\mathrm{UT}\}
$$

3 正確には複数の未知語記号を含む $n$-gram に対するの記述も必要であるが, 式が繁雑になるため, ここでは 1 つの未知 語記号のみを含む場合のみ記述した。 
と式(5)において $\boldsymbol{w}_{u}=w_{1}, \boldsymbol{w}_{v}=\varepsilon$ とすることで得られる等式

$$
f_{r}\left(w_{1} \mathrm{UT}\right)=\sum_{w \in \mathcal{X}^{+}} f_{r}\left(w_{1} w\right)-\sum_{w \in \mathcal{W}_{k}} f_{r}\left(w_{1} w\right)
$$

から以下のように単語 1-gram 頻度と既知語に対する単語 2-gram 頻度の和から計算さ れる。

$$
f_{r}\left(w_{1} \mathrm{UT}\right)=f_{r}\left(w_{1}\right)-\sum_{w \in \mathcal{W}_{k}} f_{r}\left(w_{1} w\right)
$$

同様に未知語記号と任意の単語 $w_{2} \in \mathcal{W}_{k}$ からなる列の確率的単語分割コーパスにおける 頻度 $f_{r}\left(\mathrm{UT} w_{2}\right)$ は，以下のように計算される。

$$
f_{r}\left(\mathrm{UT} w_{2}\right)=f_{r}\left(w_{2}\right)-\sum_{w \in \mathcal{W}_{k}} f_{r}\left(w w_{2}\right)
$$

さらに未知語記号の単語 2-gram 頻度 $f_{r}($ UT UT) は

$$
f_{r}(\cdot)=\sum_{w_{1} \in \mathcal{X}^{+}} \sum_{w_{2} \in \mathcal{X}^{+}} f_{r}\left(w_{1} w_{2}\right)
$$

を用いることで以下のように計算される。

$$
\begin{aligned}
f_{r}(\mathrm{UT} \mathrm{UT})= & f_{r}(\cdot)-\sum_{w_{1} \in \mathcal{W}_{k}} f_{r}\left(w_{1} \mathrm{UT}\right)-\sum_{w_{2} \in \mathcal{W}_{k}} f_{r}\left(\mathrm{UT} w_{2}\right) \\
& -\sum_{\left(w_{1} w_{2}\right) \in \mathcal{W}_{k} \times \mathcal{W}_{k}} f_{r}\left(w_{1} w_{2}\right)
\end{aligned}
$$

未知語記号を含む単語 $n$-gram 頻度 $(n \geq 3)$ 未知語記号を含む一般の $n$-gram 頻度も2gram 頻度の場合と同様に計算することが可能である.

未知語記号を含む単語 $n$-gram 確率 $(n \geq 1)$ 未知語記号を含まない場合の式 $(1)(2)$ と同 様に, 確率的単語 $n$-gram 頻度を確率的単語 $(n-1)$-gram 頻度で割ることで未知語記号 を含む単語 $n$-gram 確率が得られる。

以上から，語彙を有限とし未知語記号を仮定する場合でも，確率的単語分割コーパスに対す る単語 $n$-gram 確率を推定できることが示された.

\section{4 生コーパスの利用方法}

適応対象の分野のコーパスは，その分野の言語的な特徵を的確に捉えるために重要である. この利用方法としては，以下の 3 つが代表的である.

- 未知語の取り出し

生コーパスに対して文字 $n$-gram の統計などを取り，ある程度の頻度があ

り，かつ前後の文字の分布にばらつきがある文字列などを単語候補として 


\begin{tabular}{llll}
\hline 女性エコノミスト、キャ & サリン & ・カミリさんなどは「今 \\
ローム・デーヴイッド・ & サリン & ジャーは 20 世紀アメリカ \\
に次ぐおぞましい地下鉄 & サリン & 事件、長い不況に追い打 \\
理が始まった中川被告は & サリン & 生成を認めながら「目的 \\
っているのを知りながら & サリン & 流出を阻止する義務を怠 \\
\hline
\end{tabular}

図 2 単語リストの $\mathrm{KWIC} に よ る$ 単語境界情報付与の例

抽出する(森, 長尾 1998)(中渡瀬 1995)この結果得られた単語候補は, 人 手でチェックされる。ささらに確率的言語モデルの応用に応じて読みの付与 などを行なう。

- 自動分割による単語分割結果

自動単語分割システム (Nagata 1994) により単語境界を推定し，これを単 語分割済みコーパスとして利用する。単語分割システムは，人手により正 しく単語に分割された一般的なコーパスから構築されるので，適応対象の 分野の文に対する解析精度は必ずしも高くない. 特に，適応分野に特有の 単語や表現の周辺で分割を誤る傾向がある.しかしながら, 適応対象の分 野の単語分割済みコーパスは, 多少の誤りが含まれていても, 確率的言語 モデルの構築に有用であることが知られている。

- 人手による単語分割結果

理想的には，適応対象の分野のコーパスの全ての文が正しく(単語分割の指 針に沿って) 単語に分割されていることが望ましい。このときに確率的言語 モデルの能力は最高になる。

確率的言語モデルの能力は，単語分割の修正量を増やせば増やすほど高くなる．現実には， 単語分割の修正作業はコストや時間がかかるので，コーパスの一部分を修正の対象とし，残り の部分に関しては自動分割の結果をそのまま用いるということが行なわれる。しかし，この方 法が有限の作業量を割り当てる最良の方法であるか疑問が残る。

単語分割の修正作業は，コーパスに単語境界の情報を付与することである．単語境界の情報 の最小単位は各文字の間に単語境界があるか否かである。しかし，一般的に行なわれる修正作 業は文単位であり，文頭から順に各文字の間の単語境界情報が正しいかを確認し，必要に応じ て修正する。これに対して，我々は修正作業の単位をより細かくとること，具体的には，単語 リストなどで与えられる適応分野に特有の単語の周辺に集中することを提案する，具体的には， 図 2 に示されるように，単語リストに含まれる語(例では「サリン」)の対象分野のコーパスで の出現位置を KWIC (Key Word In Context) 形式で提示し, 注目している文字列が各文脈にお 
いて単語として用いられているかのチェックをする。単語として用いられている箇所にマーク (図中では「○」) を付け，それ以外の箇所では何もしないという作業を行なう。各単語につい てマークする箇所の数を制限するということも有効であろう。そうすれば，判断の難しい箇所 で時間を浪費することを避けることもできる。

\section{5 評価}

適応分野の生コーパスの利用方法について比較検討するために，生コーパスに対する人手に よる単語境界情報の付与の程度や方法を複数用意し，その結果得られるコーパスから推定され る確率的言語モデルの予測力やそれに基づく仮名漢字変換の精度を計算した.

\section{1 実験条件}

実験には，一般的な分野のコーパスとして会話辞典の例文と，適応対象として新聞記事を用 いた (表 1 参照). 両分野のコーパスの各文は人手で単語に分割されているが，適応分野のコー パスは，主として生コーパスとして利用される。単語分割済みコーパスとしての利用は，比較 対象としての理想的な状況を実現するためである，適応分野の単語リストは，適応分野のコー パスにのみ出現する 21,855 単語からなる.

基本となる確率的言語モデルは以下の通りである.

・ Base 単語分割済みの一般分野のコーパスから単語 2-gram モデルを構築した. 既知語の 数は 5,112 語である。適応分野の単語リストは，未知語モデルにおいて出現確率を嵩上 げされ，未知語に対して出現しやすくなる外部辞書語 (森，山地 1997) として利用する. 適応分野のコーパスは利用しない.

この確率的言語モデルの同一分野のテストコーパスに対するクロスエントロピーは 4.509 であ り，テストセットパープレキシティーは 64.28 であった ${ }^{4}$.

実験に利用した自動単語分割システムは，この言語モデルに基づいており，入力文に対して 最大確率となる単語列を返す (第 2.2 項参照). 同一分野のテストコーパスに対する単語境界の 推定精度は $98.26 \%$ であった ${ }^{5}$.

後述する実験において, 確率的単語分割コーパスの単語境界確率の推定方法としては, 自動 分割の結果を利用する方法を採用した。単語境界の推定結果の信頼度には，自動単語分割シス テムの精度 $\alpha=98.26 \%$ を利用した。すなわち，自動単語分割システムにより単語境界である と判定された点では $P_{i}=\alpha$ とし, 単語境界でないと判定された点では $P_{i}=1-\alpha$ とした.

4 テストセットパープレキシティーは平均単語長に影響されるので, 異なるテストコーパスに対する結果との比較には適 さない.

5 対象分野のテストコーパス (表 1 参照) に対する単語境界の推定精度は $89.25 \%$ あった. 
表 1 コーパス

\begin{tabular}{c|c|r|r|r}
\hline \hline 用途 & 分野 & \multicolumn{1}{|c|}{ 文数 } & \multicolumn{1}{c}{ 単語数 } & \multicolumn{1}{c}{ 文字数 } \\
\hline 学習 & 会話 & 14,754 & 187,658 & 254,436 \\
学 & 新聞 & 20,700 & 625,761 & 917,830 \\
テスト & 会話 & 1,639 & 21,105 & 28,655 \\
テスト & 新聞 & 2,300 & 68,566 & 100,091 \\
\hline
\end{tabular}

\section{2 評価基準}

確率的言語モデルの予測力の評価に用いた基準は, 文字単位のクロスエントロピーと単語あ たりのテストセットパープレキシティーである. まず，テストコーパス $C_{t}$ に対して未知語の予 測も含む文字単位のエントロピー $H$ を以下の式で計算する (Brown, Pietra, and Mercer 1992).

$$
H=-\frac{1}{\left|C_{t}\right|} \log _{2} \prod_{\boldsymbol{w} \in C_{t}} M_{w, n}(\boldsymbol{w})
$$

ここで, $\left|C_{t}\right|$ はテストコーパス $C_{t}$ の文字数を表す. 次に, 単語単位のテストセットパープレキ シティを以下の式で計算する。

$$
P P=2^{H \times \overline{|\boldsymbol{w}|}}
$$

ここで $\overline{|\boldsymbol{w}|}$ は平均単語長 (文字数) である.

さらに確率的言語モデルの応用として仮名漢字変換 (森他 1999) を採用し，文単位で一括変 換した場合の第一候補の変換精度を計算した 6 .これは，音声認識において，音響モデルの誤り の影響を排した場合と考えることもできる。

\section{3 適応分野の生コーパスの利用方法}

適応分野の生コーパスの利用方法について比較検討するために，生コーパスの自動分割結果 に対する単語境界情報の人手による修正の程度や方法として，以下の 6 つを準備した。

- Auto 適応分野の生コーパスを自動的に単語分割し，その結果をそのまま用いる。これ は, 自動分割システムにより単語境界と判定された点では $P_{i}=1$ とし，単語境界でない と判定された点では $P_{i}=0$ とする確率的単語分割コーパスと等価である.

- Raw 適応分野の生コーパスを確率的単語分割コーパスとして用いる.すなわち, 自動単 語分割システムにより単語境界であると判定された点では $P_{i}=\alpha$ とし, 単語境界でない と判定された点では $P_{i}=1-\alpha$ とした.

- Well-done 適応分野の生コーパスの全文を人手により正しく単語に分割し，これを Auto と同様に決定的に単語に分割されたコーパスとして利用する。

• 45\%-done＼cjkstart適応分野の生コーパスの最初から 281,398 単語目まで $(45.00 \%)$ を人手により 6 評価基準は文献 (森他 1999) と同一である. 
表 2 各モデルの予測精度と仮名漢字変換の精度

\begin{tabular}{c|c|c|c|c|c}
\hline \hline モデル & $\begin{array}{c}\text { 生コーパス } \\
\text { の利用方法 }\end{array}$ & $H$ & $P P$ & 再現率 & 適合率 \\
\hline Base & - & 7.558 & 1938 & $62.74 \%$ & $72.34 \%$ \\
\hline Auto & 自動分割 & 6.618 & 755.7 & $80.52 \%$ & $85.24 \%$ \\
Raw & 確率分割 & 6.276 & 536.5 & $84.70 \%$ & $87.85 \%$ \\
\hline Rare & 部分修正 & 6.133 & 465.2 & $86.57 \%$ & $89.24 \%$ \\
Medium & 部分修正 & 5.889 & 364.2 & $88.34 \%$ & $90.50 \%$ \\
$45 \%$-done & 部分修正 & 6.049 & 427.4 & $86.56 \%$ & $89.32 \%$ \\
Well-done & 完全修正 & 5.858 & 353.1 & $88.90 \%$ & $90.90 \%$ \\
\hline
\end{tabular}

正しく単語に分割し，その残りを自動的に単語分割した。これをAuto と同様に決定的 に単語に分割されたコーパスとして利用する。

・Medium まずRawと同様に単語境界確率を設定する。さらに，単語りストに含まれる文 字列が生コーパス中に単語として出現している全ての箇所において, その文字列内の単 語境界確率を 0 とし, その文字列の直前と直後の単語境界確率を 1 とする。これは，生 コーパスに対する単語リストに含まれる文字列の KWIC を見て，その文字列が単語とし て出現している場合にマークをつける作業をした結果に相当する。マーク箇所は単語数 でのべ 138,483 箇所 $(22.13 \%)$ である.

・Rare まずRaw と同様に単語境界確率を設定する。さらに，単語リストに含まれる文字 列が生コーパス中に単語として出現している最初の 2 箇所において，その文字列内の単 語境界確率を 0 とし, その前後の単語境界確率を 1 とする。これは, 生コーパスに対す る単語リストに含まれる文字列の KWIC を見て, その文字列が単語として出現している 場合にマークをつける作業を各文字列に対して 2 つマークがつくまで行なった結果に 相当する。マーク箇所は単語数でのべ 32,643 箇所 $(5.22 \%)$ である.

以上のようにして得られる適応分野のコーパスから，Base モデルの既知語と単語リストに 含まれる単語を語彙として単語 1-gram 確率と単語 2-gram 確率を計算し, Base モデルと補間 して適応分野のための確率的言語モデルを構築した.

\section{4 評価}

各モデルの予測力と仮名漢字変換の精度を表 2 に示す. Base とコーパス修正のコストがな いAuto と Rawの結果から，適応分野のコーパスは可能な限り収集し，言語モデルの推定に利 用するのがよいといえる，利用方法においては，Auto と Rawの結果の比較から，誤りを含む 自動分割結果を $100 \%$ 信頼してそのまま用いるのではなく，単語境界か否かの判定結果を割り引 いて, 確率的単語分割コーパスとして用いるほうがよいといえる。

コーパス修正のコストがないRawの予測力や変換精度は，自動分割の結果を人手で完全に 
修正した場合の Well-doneの予測力と変換精度に対してかなり低く，修正のコストを払うこと で改善する余地があることが分かる。自動分割結果の修正は文単位で行なうのが一般的である が，単語リストに含まれる単語が出現する箇所に限定して，文の一部分のみをチェックする場 合の結果がRare と Medium である. 単語リストの各単語に対して 2 箇所の出現のみを人手で マークするRare では, 単語数の割合にして $5.22 \%$ みがマークの対象になるが，仮名漢字変換 の精度はコーパスの最初から順に $45.00 \%$ 単語をチェックする 45\%-doneの精度にほぼ等しい. 単語リストの各単語に対して全ての出現箇所を人手でチェックする Medium と自動分割の結果 を人手で完全に修正するWell-doneの予測力と変換精度は同程度である.この結果から, 適応 分野に特有の語彙の出現箇所に修正のコストを集中すれば，コーパス全体の約 $22.13 \% の$ 単語の みのチェックで, 予測力においても, 仮名漢字変換の精度においても，コーパス全体の分割結 果を人手で修正したコーパスを利用する場合にかなり近い性能を達成することが可能であると いえる.

文単位で分割結果を修正する方法と，特定の文字列の KWIC を見てそれが各文脈で単語と して用いられているかをマークするするのは，1単語あたりのチェックに要するコストが等しい とは限らない.しかしながら, Rare と 45\%-doneのチェック対象の単語数には 9 倍の差がある. 特定の単語の KWIC における 1 箇所のマークが, 注目単語の前後 4 単語の修正を含めた分割修 正 (合計 9 単語) に相当する時間を要するとは思えず, Rare と 45\%-doneの総修正コストの順序 関係は変わらないであろう。加えて, 文全体に対して分割結果の修正を行なう場合には, 主に 活用語尾や助詞や助動詞からなる, 文法の専門家でさえも正確な単語分割が容易でない箇所が 含まれることになる。このような正確な単語分割が困難な機能語などの列の分割方針を作業者 に徹底することは非常に困難である。単語リストに含まれる単語のみをチエック対象にすれば, このような困難を回避することが可能となり, さらに, 適応分野に特有の単語の統計的な振る 舞いを捕捉するという, 適応分野のコーパスを利用する本来の目的のみにコーパス修正のコス 卜を集中することが可能となる，以上のことから，適応分野に特有の語彙の出現箇所に修正の コストを集中し，この結果得られる部分的に修正されたコーパスを確率的単語分割コーパスと みなして確率的言語モデルを構築することにより, 音声認識や仮名漢字変換などの適応対象の 分野における精度をより低いコストでより短時間で向上させることが可能となる。

\section{6 おわりに}

企業ソリューションとして音声認識などの音声言語処理技術が求められる場合, 技術を適応 する分野の単語リストと生コーパスのみが利用可能であることが多い. 本論文では，このよう な状況を前提として, 確率的言語モデルを分野適応する際に, コーパスの修正の程度や方法に ついて比較検討を行なった。

予測力や仮名漢字変換の精度を評価基準とする実験の結果, 生コーパスの自動単語分割の結 
果の人手による修正を単語リストに含まれる単語が出現する箇所に限ることで, 確率的言語モ デルの適応分野における性能をより効率よく向上させることが可能となることが分かった.

\title{
略歴
}

森 信介: 1998 年京都大学大学院博士後期課程修了. 同年日本アイ・ビー・エ ム (株) 入社. 東京基礎研究所において計算言語学の研究に従事. 工学博士. 1997 年情報処理学会山下記念研究賞受賞. 情報処理学会会員.

\author{
(2006 年 3 月 1 日受付) \\ (2006 年 6 月 29 日 再受付) \\ (2006 年 7 月 13 日採録)
}

\section{参考文献}

Brown, P. F., Cocke, J., Pietra, S. A. D., Pietra, V. J. D., Jelineck, F., Lafferty, J. D., Mercer, R. L., and Roossin, P. S. (1990). "A Statistical Approach to Machine Translation." Computational Linguistics, 16 (2), pp. 79-85.

Brown, P. F., Pietra, S. A. D., and Mercer, R. L. (1992). "An Estimate of an Upper Bound for the Entropy of English." Computational Linguistics, 18 (1), pp. 31-40.

Hakkani-Tür, D., Tur, G., Rahim, M., and Riccardi, G. (2004). "Unsupervised and Active Learning in Automatic Speech Recognition For Call Classification." In Proceedings of the International Conference on Acoustics, Speech, and Signal Processing.

Jelinek, F. (1985). "Self-Organized Language Modeling for Speech Recognition." Tech. rep., IBM T. J. Watson Research Center.

Mori, S. and Takuma, D. (2004). "Word N-gram Probability Estimation From A Japanese Raw Corpus." In International Conference on Speech and Language Processing.

Nagata, M. (1994). "A Stochastic Japanese Morphological Analyzer Using a Forward-DP Backward-A* N-Best Search Algorithm." In Proceedings of the 15th International Conference on Computational Linguistics, pp. 201-207.

Nagata, M. (1996). "Context-Based Spelling Correction for Japanese OCR." In Proceedings of the 16th International Conference on Computational Linguistics.

西村雅史, 伊東伸泰, 山崎一孝, 荻野紫穂 (1997). “単語を認識単位とした日本語ディクテーショ ンシステム.”情報処理学会研究報告, SLP15 巻, pp. 27-34.

中渡瀬秀一 (1995). “統計的手法による単語の切り出しについて.” 電子情報通信学会技術研究 会報告, pp. 69-74. 
森信介, 土屋雅稔, 山地治, 長尾真 (1999). “確率的モデルによる仮名漢字変換.”情報処理学会 論文誌, 40 (7), pp. 2946-2953.

森信介, 山地治 (1997). “日本語の情報量の上限の推定.” 情報処理学会論文誌, 38 (11), pp. 2191-2199.

森信介, 長尾眞 (1998). “ $n$ グラム統計によるコーパスからの未知語抽出.”情報処理学会論文 誌, 39 (7).

下岡和也, 南條浩輝, 河原達也 (2004). “講演の書き起こしに対する統計的手法を用いた文体の 整形.” 自然言語処理, 11 (2), pp. 67-83. 